\title{
Anionic dye (acid green 25) adsorption from water by using polyaniline nanotubes salt/silica composite
}

\author{
Mohamad M Ayad ${ }^{1,2^{*}}$ and Ahmed Abu El-Nasr ${ }^{2}$
}

\begin{abstract}
Acid green 25 (AG) dye was adsorbed from water by using polyaniline nanotubes (PANI NT) salt/silica composite as adsorbent. Comparison between the removal of the dye by using PANI NT salt/silica composite and the conventional PANI salt/silica composite was investigated. This result was evidenced from the measurements of the UV-visible absorbance of AG dye solutions after different times. Experiments were conducted by varying parameters, namely initial concentration of the dye and contact time. The percentage of color removal decreased with increase in initial dye concentration. Adsorption equilibrium of color removal was reached after 60 min of contact time. Equilibrium data were fitted to Langmuir, Freundlich, and Tempkin isotherms, and their constants were determined. Using the linear correlation coefficients showed that the Langmuir isotherm best fits the AG adsorption data on PANI NT salt/silica composite. The experimental data were fitted into the following kinetic models: pseudo-first-order, pseudo-second-order, and the intraparticle diffusion model. It was observed that the pseudo-second-order kinetic model described the adsorption process better than any other kinetic models. The results obtained indicate that PANI NT salt/silica composite could be employed as a much more efficient adsorbent than the conventional PANI salt/silica composite for dye removal from water.
\end{abstract}

Keywords: Polyaniline nanotube salt/silica composite, Acid green 25, Adsorption isotherm, Kinetics

\section{Background}

Industrial effluents are one of the major causes of environmental pollution because effluents discharged from dyeing industries are highly colored with a large amount of suspended organic solid [1]. Untreated disposal of this colored water into the receiving water body either causes damage to aquatic life or to human beings by mutagenic and carcinogenic effect. As a matter of fact, the discharge of such effluents is worrying for both toxicological and environmental reasons [2]. Dyes can be classified as anionic (acid dyes), cationic (basic dyes), and non-ionic (disperse dyes) [3]. Acid dyes are organic sulfonic acids; the commercially available forms are usually sodium salts, which exhibit good water solubility. In sequence of their importance, acid dyes are mostly used with certain fiber types such as polyamide,

\footnotetext{
* Correspondence: mohamad.ayad@ejust.edu.eg

'Department of Chemical and Petrochemical Engineering, Egypt-Japan University of Science and Technology, Borg El Arab, Alexandria 21934, Egypt ${ }^{2}$ Department of Chemistry, Faculty of Science, University of Tanta, Tanta 31111, Egypt
}

\section{Springer}

(C) 2012 Ayad and El-Nasr; licensee Springer. This is an Open Access article distributed under the terms of the Creative Commons Attribution License (http://creativecommons.org/licenses/by/2.0), which permits unrestricted use, distribution, and reproduction in any medium, provided the original work is properly cited. wool, silk, modified acrylic, and polypropylene fibers as well as blends of the aforementioned fibers with other fibers such as cotton, rayon, polyester, regular acrylic [4], etc. Various techniques like precipitation, membrane filtration, coagulation, electrochemical, ion exchange, chemical oxidation, adsorption $[5,6]$, etc. are used for the removal of dyes from wastewater. Adsorption is a procedure of choice for the removal of dyes from wastewater [7]. The major advantages of this technique are its low generation of residues and the possibility of its adsorbent being recycled and reused [8]. Several effective, selective, and cheaper adsorbent materials were developed such as waste orange peel [9], banana pith [10], rice husk [11], clay [12], neem leaf powder [13], powdered activated sludge [14], and activated carbon/charcoal [15]. Recently, conducting polymer was tested in the adsorption of dye effluent [16-18].

Composites which are formed by the incorporation of organic-inorganic materials are very fruitful enterprise as the merits of organic and inorganic moieties can be combined in the composites. Polyaniline (PANI) is one 
of the organic conducting polymers that can be used as an electrode material [19], in microelectronics [20], as an electrochromic device [21], in radiation shielding, and in recordable optical disks [22]. It was also reported to be utilized as an adsorbent for the adsorption of protein [23] and DNA [24]. Polyaniline is considered to be one of the most promising classes of polymers due to their well-behaved electrochemistry, easy protonation reversibility, excellent redox recyclability [25], good environmental stability [26], electrochromism [27], easy doping [28], and easy preparation. The properties of PANI can be improved by incorporating other functional materials, including oxides, polyacidic anions, etc. [29]. Among those inorganic moieties in the organic-inorganic composites, silica has received great attention because of its unique properties and wide applications [30]. Silica particles have been included in the composites through many ways, including surface polymerization of aniline adsorbed onto silica surfaces [31], in situ hydrolysis and condensation of tetraethoxysilane in PANI solutions or on solid PANI surfaces [32], etc. Although silica is insulating, some of the composites were in the same conductivity level as that of PANI [32], and some even displayed enhanced conductivity [32], providing potential applications of the composites in electrochemistry and related fields. Aniline polymerization in an aqueous acidic medium yields the most conductive form of PANI; the emeraldine salt (ES) was deprotonated by treatment with an alkali to polyaniline emeraldine base (EB) [33], as shown in Scheme 1. Recently, we have explored PANI coating on the electrode of the quartz crystal microbalance as chlorinated hydrocarbon and alcohol vapor [34-36] sensors. The diffusion and the adsorption kinetics of the adsorbed vapors into the polymer were studied.

Nanostructured PANI receives a great deal of attention due to its properties which differ from those of the coarse structures. The increasing surface area of PANI makes it an interesting material for sensor construction and gas storage [37]. Recently, PANI nanotubes (NT) were used for the reduction of silver nitrate to produce PANI-silver nanoparticle composites [38]. Also, the PANI NT base has been utilized as an adsorbent for the removal of cationic dyes such as MB from aqueous solution [39]. It has been concluded that the NTs provide a more efficient adsorbent than conventional PANI. The kinetic mechanism and the isotherm models were investigated. In the same context, the present paper was devoted to study the adsorption of the anionic acid green 25 dye (AG) as a model onto PANI NT salt/silica composite by using UV-visible spectroscopy. The difference between PANI NT salt/silica composite and the conventional PANI salt/silica composite in the adsorption of AG was studied.

\section{Results and discussion}

Scanning electron microscopy (SEM) was used to provide morphological information of both the PANI NT salt and PANI NT salt/silica composite, Figure 1a,b, respectively. It can be seen that the NTs are of 100 to 300 $\mathrm{nm}$ in diameter. The lengths of PANI NTs were 2 to 40 $\mu \mathrm{m}$. The cavities in the NTs were easily visible (Figure 1a). The inner diameter differed substantially among the individual NTs, in the range of 20 to $250 \mathrm{~nm}$, but it was relatively constant within each individual nanotube. Some nanorods with no cavities were also formed. These nanostructures obtained in the present study are similar to those reported in the bulk solution [40]. Figure 1b shows the SEM image of the PANI NT/silica composite with silica particles that appear as cluster spot. The PANI NT salt composite plays an important role in the enhancement of polymer surface area and helps in increasing the adsorption rate of polymer towards the dye.

\section{Adsorption of AG onto the PANI NT salt/silica composite Adsorption studies}

The adsorption of AG onto the PANI NT salt, the conventional PANI, and their composites with silica composite was tested using UV-visible spectroscopy. Adding $0.05 \mathrm{~g}$ of different substrates such as PANI NT salt/silica composite, conventional PANI salt/silica composite, PANI NT salt, and conventional PANI salt to $18.6 \mathrm{mg} \mathrm{L}^{-1}$ AG

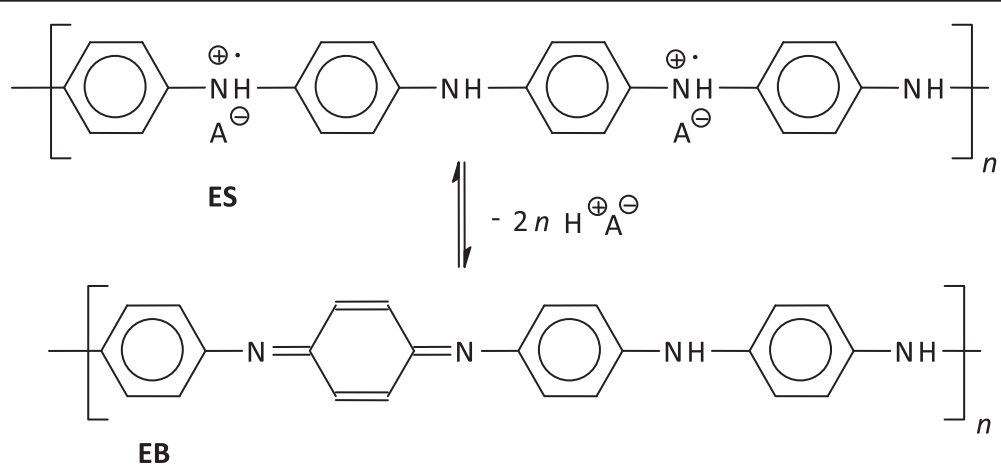

Scheme 1 Protonated (doped) polyaniline ES is deprotonated (dedoped) by treatment with an alkali to polyaniline EB. 

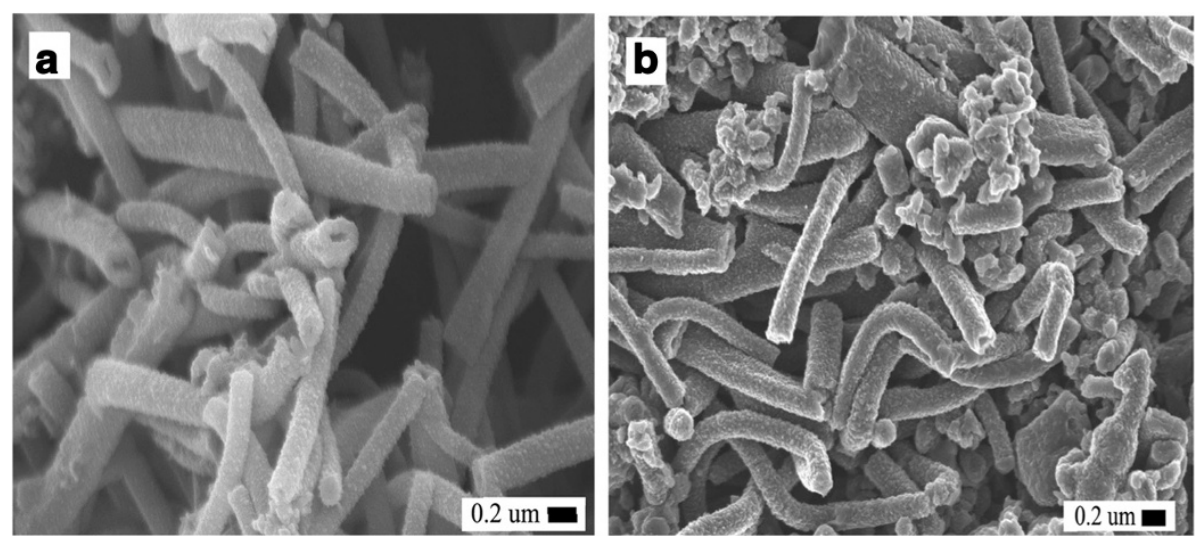

Figure 1 SEM images of PANI NT salt (a) and PANI NT salt/silica composite (b).

solution at the same conditions leads to a decrease in the absorbance of AG with increasing time (Figure 2a,b,c,d, respectively). The amount of dye adsorbed, $Q_{e}\left(\mathrm{mg} \mathrm{g}^{-1}\right)$, onto per unit weight of PANI NT salt/silica composite, PANI NT salt, conventional PANI salt/silica composite, and conventional PANI salt at equilibrium is equal to 3.73 , $3.56,3.51$, and $1.48 \mathrm{mg} \mathrm{g}^{-1}$, respectively. Figure 3 shows the decrease in AG concentration at different times in the presence of PANI NT salt/silica composite. The amount of dye adsorbed into per unit weight of the polymer adsorbent, $Q_{e}\left(\mathrm{mg} \mathrm{g}^{-1}\right)$, was calculated from the mass balance equation given by

$$
Q_{e}=\left(C_{0}-C_{e}\right) V m^{-1}
$$

where $C_{0}$ is the initial dye concentration in liquid phase $\left(\mathrm{mg} \mathrm{L}^{-1}\right), C_{e}$ is the liquid-phase dye concentration at equilibrium $\left(\mathrm{mg} \mathrm{L}^{-1}\right), V$ is the volume of the dye solution used (L), and $m$ is the mass of the adsorbent used (g). It is observed that adsorption amount increases in the following order: PANI NT salt/silica composite $>$ PANI NT salt $>$ conventional PANI salt/silica composite > conventional PANI salt. The extent of AG dye adsorption onto the PANI NT salt/silica composite is highly accessible as compared to the other substrates. This result is explained by the higher surface area of the PANI NT salt/silica composite. The binding sites of the interactions available in the PANI NT salt/silica composite would be larger; hence, more interaction with the anionic dye AG occurred. The dye adsorption kinetics and isotherms of the PANI NT salt/silica composite will be studied in full details in the following sections.

\section{Adsorption kinetics}

In order to evaluate the kinetic mechanism which controls the process, the pseudo-first-order [41], pseudo-secondorder [42], and intraparticle diffusion [43] models were tested, and the validity of the models were verified by the linear equation analysis $\log \left(Q_{e}-Q_{t}\right)$ vs. $t,\left(t / Q_{t}\right)$ vs. $t$, and $Q_{t}$ vs. $t^{1 / 2}$, respectively. Good correlation with the kinetic data explains the dye adsorption mechanism in the solid phase [41-43].

The first model is the pseudo-first-order rate equation:

$$
\log \left(Q_{e}-Q_{t}\right)=\log Q_{e}-\frac{k_{1}}{2.303} t
$$

where $Q_{e}$ and $Q_{t}\left(\mathrm{mg} \mathrm{g}^{-1}\right)$ refer to the amount of dye adsorbed at equilibrium and time $t$ ( $\mathrm{min})$, respectively, and $k_{1}$ is the rate constant. Figure 4 a shows the plot of the pseudo-first-order, and the parameters $k_{1}, Q_{e}$, and the correlation coefficient $\left(R^{2}\right)$ values were determined (Table 1). The curve-fitting plots with correlation coefficient $\left(R^{2}=0.9894\right)$ are shown. The second model, the pseudo-second-order reaction, is dependent on the amount of solute adsorbed on the surface of the adsorbent and the amount adsorbed at equilibrium.

The pseudo-second-order model can be represented in the following form:

$$
t / Q_{t}=1 / k_{2} Q_{e}^{2}+t / Q_{e}
$$

where $k_{2}$ is the rate constant of the pseudo-second-order model $\left(\mathrm{g} \mathrm{mg}^{-1} \mathrm{~min}^{-1}\right)$. Figure $4 \mathrm{~b}$ shows the curve-fitting plot of Equation $3\left(\left(t / Q_{t}\right)\right.$ vs. $\left.t\right)$, and the parameter values of $k_{2}, Q_{e}$, and $R^{2}$ were determined (Table 1$)$. The curvefitting plots with excellent linearity $\left(R^{2}=0.9995\right)$ confirm the applicability of the pseudo-second-order equation.

The third model is an intraparticle diffusion model. Weber and Morris [44] stated that if intraparticle diffusion is the rate-controlling factor, uptake of the adsorbate varies with the square root of time. The root time dependence was expressed by Equation 4:

$$
Q_{t}=k_{\mathrm{i}} t^{1 / 2}+C
$$

where $k_{\mathrm{i}}$ is an intraparticle diffusion rate parameter. Figure 4c shows a plot of $Q_{t}$ vs. $t^{1 / 2}$. 

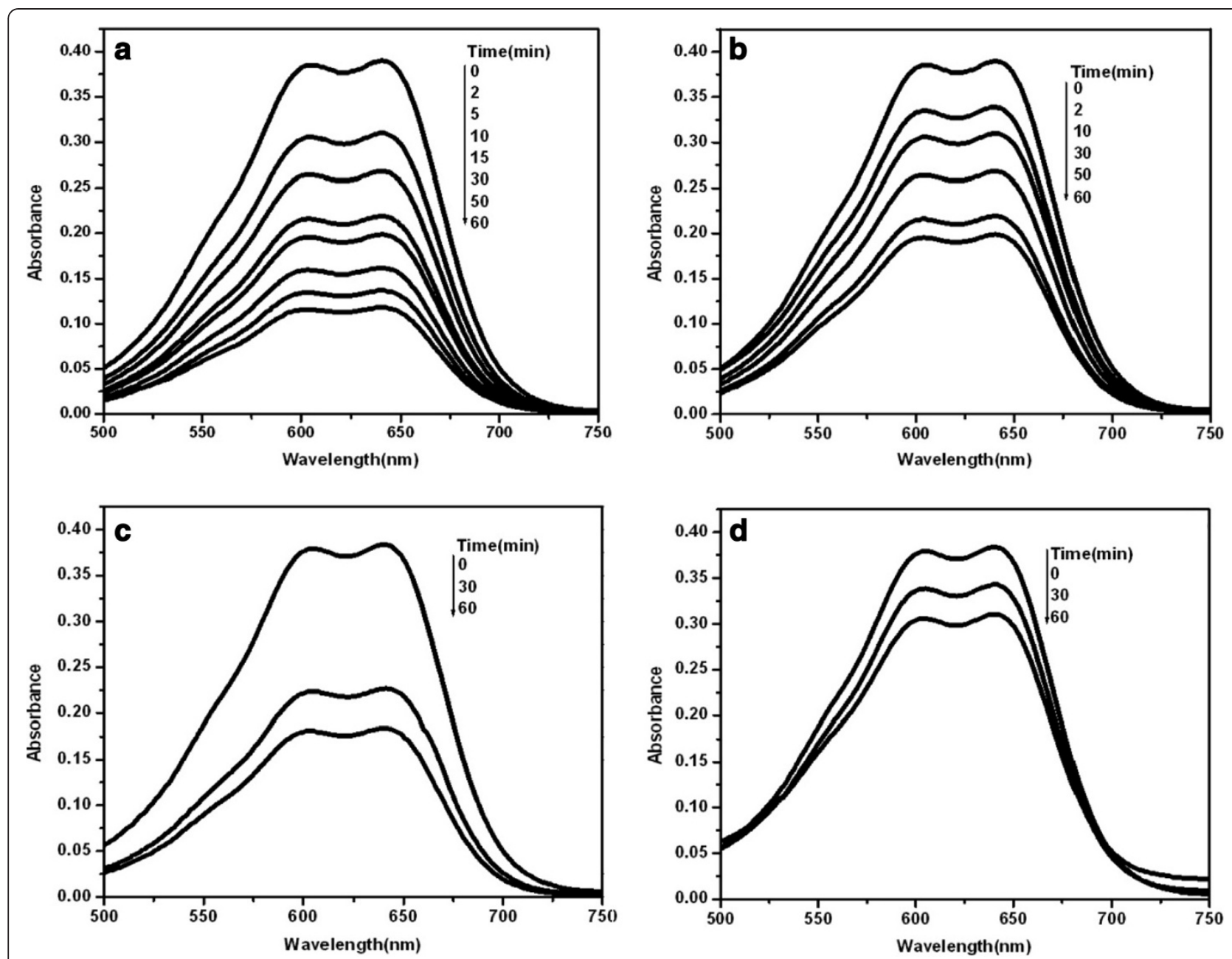

Figure 2 Time-resolved absorption spectra of AG dye adsorption (18.6 $\mathrm{mg} \mathrm{L}^{-1}$ ). With $0.05 \mathrm{~g}$ PANI NT salt/silica composite (a), $0.05 \mathrm{~g}$ conventional PANI salt/silica composite (b), $0.05 \mathrm{~g}$ PANI NT salt (c), and $0.05 \mathrm{~g}$ conventional PANI salt (d) in the dark at $25^{\circ} \mathrm{C}$.

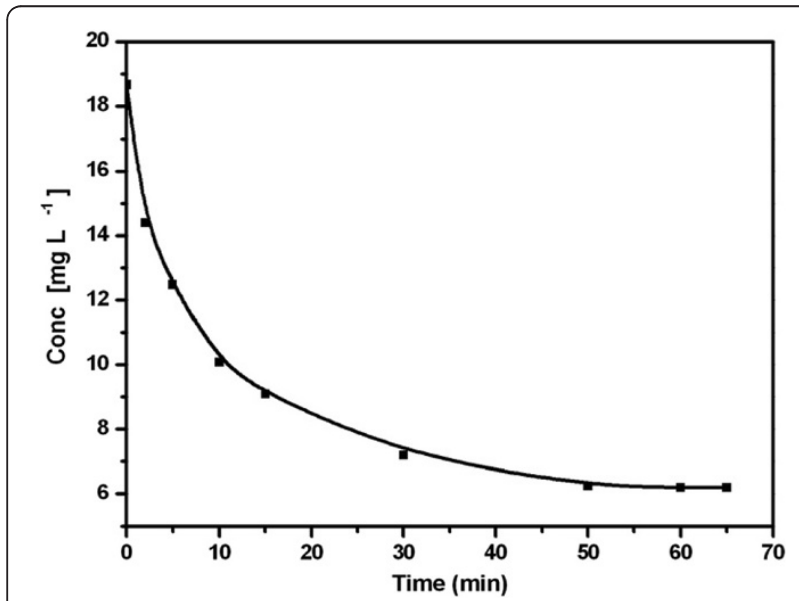

Figure 3 Concentration profile of AG dye with time in the presence of PANI NT salt/silica composite.
As shown in Figure 4c the external surface adsorption (stage 1) is the fastest and completed before $10 \mathrm{~min}$, and then, the stage of intraparticle diffusion control (stage 2) is attained and continues from 10 to $60 \mathrm{~min}$. The slope of the first linear portion (stage 2) characterizes the rate parameter corresponding to the intraparticle diffusion, whereas the intercept of this portion is proportional to the boundary layer thickness. The $R^{2}$ value for this diffusion model is 0.9851 , and the other values were determined (Table 1). This indicates that the adsorption of AG onto PANI NT salt/silica composite can be followed by an intraparticle diffusion in about $60 \mathrm{~min}$. However, the lines do not pass through the origin (the plots have intercept of $0.62 \mathrm{mg} \mathrm{g}^{-1}$ ), indicating that intraparticle diffusion is involved in the adsorption process but it is not the only rate-limiting mechanism and that some other mechanisms also play an important role. Surface adsorption and intraparticle diffusion were likely to take place simultaneously. 

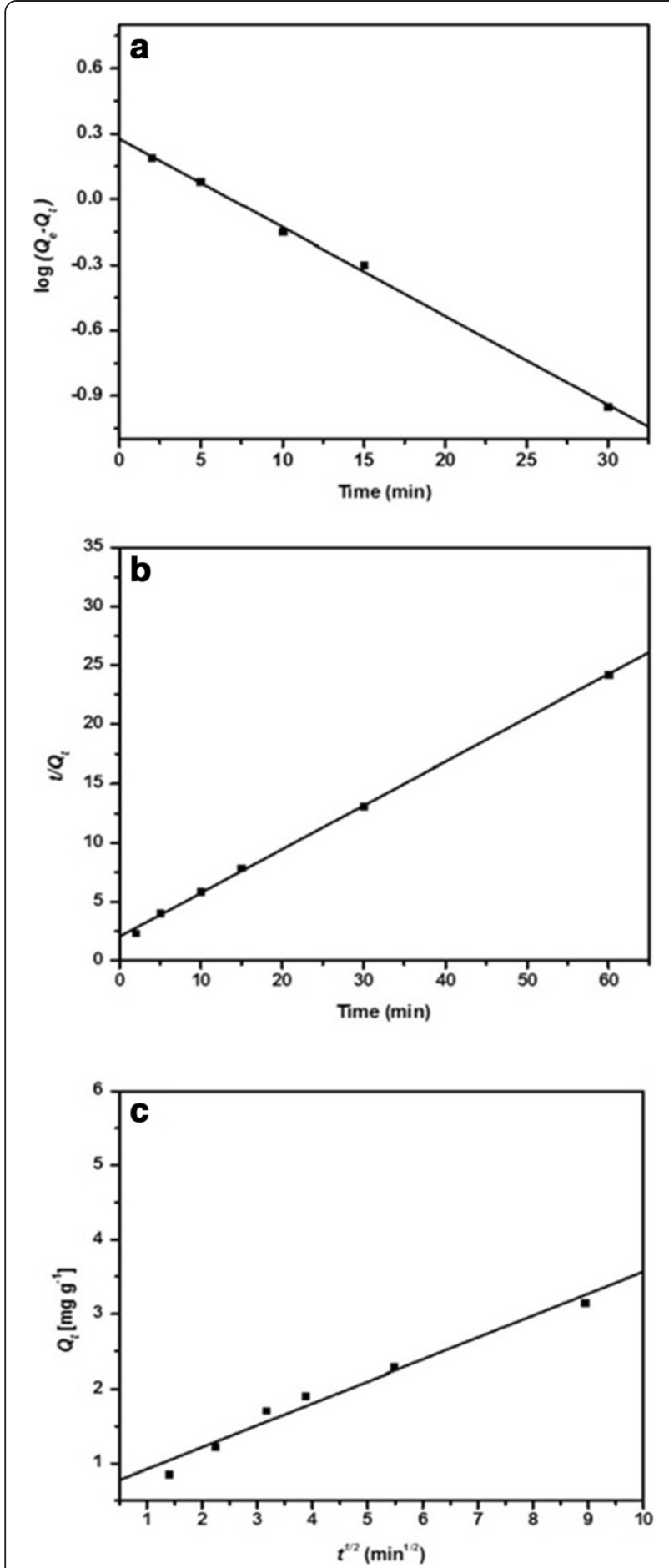

Figure 4 Kinetic plot for AG adsorption onto PANI NT salt/silica composite. (a) The pseudo-first-order, (b) pseudo-second-order, and (c) intraparticle diffusion kinetic plot for the adsorption of AG onto PANI NT salt/silica composite (dye concentration, $18.6 \mathrm{mg} \mathrm{L}^{-1}$; adsorbent dose, $0.05 \mathrm{~g} ; \mathrm{T}=25^{\circ} \mathrm{C}$ ).

\section{Adsorption isotherms}

The most common adsorption models were used to fit the experimental data Langmuir [45], Freundlich [45],
Table 1 Kinetic parameters for the adsorption of AG onto PANI NT salt/silica composite

\begin{tabular}{lll}
\hline Models & Model coefficients & $\boldsymbol{R}^{\mathbf{2}}$ \\
\hline Pseudo-first-order & $Q_{e}=1.89 \mathrm{mg} \mathrm{g}^{-1}$ & 0.9894 \\
& $k_{1}=0.092 \mathrm{~min}^{-1}$ & \\
Pseudo-second-order & $Q_{e}=2.7 \mathrm{mg} \mathrm{g}^{-1}$ & 0.9995 \\
& $k_{2}=0.67 \mathrm{~g} \mathrm{mg}^{-1} \mathrm{~min}^{-1}$ & \\
Intraparticle diffusion & $k_{\mathrm{i}}=0.29 \mathrm{mg} \mathrm{g}^{-1} \mathrm{~min}^{-1}$ & 0.9851 \\
& $t^{1 / 2}=3.97 \mathrm{~min}^{-1}$ & \\
& $C=0.62 \mathrm{mg} \mathrm{g}^{-1}$ & \\
\hline
\end{tabular}

$25^{\circ} \mathrm{C}$; initial AG concentration $=18.6 \mathrm{mg} \mathrm{L}^{-1}$.

and Tempkin [45] isotherms. The first model is the Langmuir isotherm, which is given as

$$
C_{e} / Q_{e}=1 / K_{l}+a_{l} C_{e} / K_{l}
$$

where $C_{e}$ is the equilibrium concentration of the adsorbate $\left(\mathrm{mg} \mathrm{L}^{-1}\right), Q_{e}$ is the amount adsorbed per unit mass of adsorbent $\left(\mathrm{mg} \mathrm{g}^{-1}\right), K_{l}\left(\mathrm{~L} \mathrm{mg}^{-1}\right)$ is a constant related to the affinity between the adsorbent and the adsorbate, $K_{l} / a_{l}$ is the theoretical monolayer saturation capacity $Q_{0}$. A linear plot was obtained when $C_{e} / Q_{e}$ was plotted against $C_{e}$, as shown in Figure 5a. The correlation coefficient $R^{2}$ was calculated and equals 0.9961 .

The second model is the Freundlich model, which is given by

$$
\ln Q_{e}=\ln K_{f}+1 / n \ln C_{e}
$$

where $n$ is the Freundlich constant, and $K_{f}\left(\left(\mathrm{~L} \mathrm{mg}^{-1}\right) 1 / \mathrm{n}\right)$ is the constant correlated to the maximum adsorption capacity. Figure $5 \mathrm{~b}$ shows that the plots of $\ln Q_{e}$ vs. $\ln$ $C_{e}$ are linear with $R^{2}$ equals 0.9945 .

The third model is the Tempkin isotherm, which is represented by the following equation:

$$
Q_{e}=B \ln K_{t}+B \ln C_{e}
$$

$K_{t}$ is the equilibrium binding constant and corresponds to the maximum binding energy, and $B$ is the constant related to the heat of adsorption. A linear plot was obtained when $Q_{e}$ was plotted against $\ln C_{e}$, as shown in Figure $5 \mathrm{c}$. The $R^{2}$ was calculated and equals 0.9703 .

The results obtained from the adsorption isotherms for the dye by the polymer are shown in Table 2. For the three studied systems, the Langmuir isotherm correlated better than the Freundlich and Tempkin isotherms. The Langmuir adsorption isotherm is the most widely used for the adsorption of a pollutant from a liquid solution, assuming that the adsorption takes place at specific homogeneous sites within the adsorbent [46].

The essential feature of the Langmuir isotherm can be expressed in terms of a dimensionless factor called 

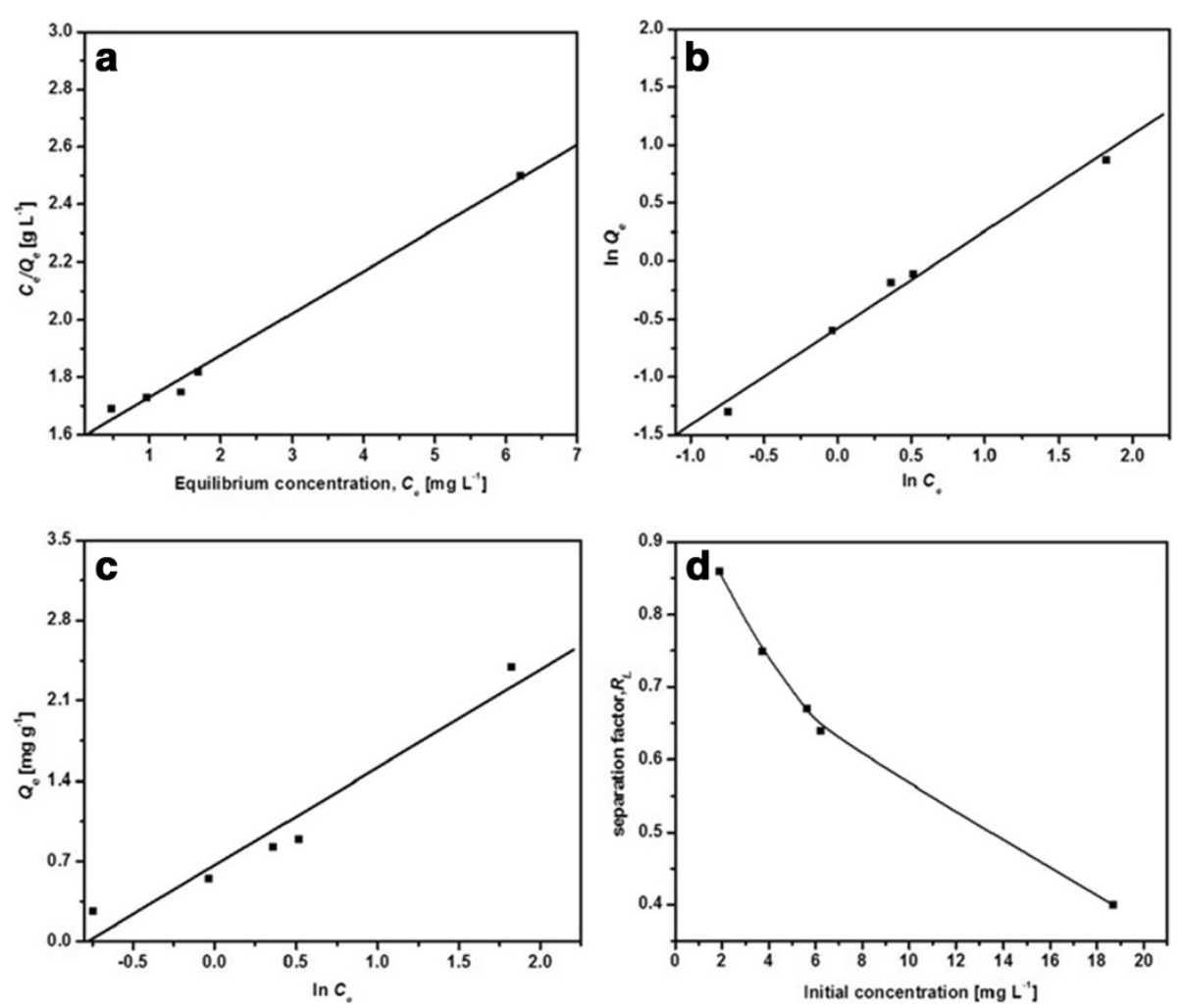

Figure 5 Adsorption isotherm models. (a) Langmuir isotherm model, (b)

(b) Freundlich isotherm model, (c) Tempkin isotherm model, and (d) separation factor vs. initial AG concentration.

separation factor $\left(R_{L}\right)$, which is defined by the following equation [47]:

$$
R_{L}=1 /\left(1+a_{l} C_{0}\right)
$$

where $C_{0}\left(\mathrm{mg} \mathrm{L}^{-1}\right)$ is the initial adsorbate concentration, and $a_{l}\left(\mathrm{~L} \mathrm{mg}^{-1}\right)$ is the Langmuir constant related to the

Table 2 Summary of the Langmuir, Freundlich, and Tempkin isotherm constants, separation factor and linear regression coefficients

\begin{tabular}{ll}
\hline Model & Parameters \\
\hline Langmuir & $Q_{0}=6.896 \mathrm{mg} \mathrm{g}^{-1}$ \\
& $K_{L}=0.6 \mathrm{~L} \mathrm{~g}^{-1}$ \\
& $a_{L}=0.087 \mathrm{~L} \mathrm{mg}^{-1}$ \\
& $R_{L}=0.38$ \\
& $R^{2}=0.9961$ \\
Freundlich & $K_{f}=0.56 \mathrm{~L} \mathrm{~g}^{-1}$ \\
& $n=1.19$ \\
Tempkin & $R^{2}=0.9945$ \\
& $K_{t}=2.18 \mathrm{~L} / \mathrm{mg}^{-1}$ \\
& $B=0.85$ \\
& $R^{2}=0.9703$ \\
\hline
\end{tabular}

energy of adsorption. The value of $R_{L}$ indicates the shape of the isotherm to be either unfavorable $\left(R_{L}>1\right)$, linear $\left(R_{L}=1\right)$, favorable $\left(0<R_{L}<1\right)$ or irreversible $\left(R_{L}=0\right)$. Figure $5 \mathrm{~d}$ shows the variation of $R_{L}$ with initial AG concentrations.

The results indicate that $R_{L}$ values were in the range of 0 to 1 , indicating that the adsorption of AG onto PANI NT salt/silica composite is favorable. The observed rate constant $K_{\text {obs, }}$ is equal to $0.037 \mathrm{~min}^{-1}$, and it was calculated from Figure 6 by using the following equation:

$$
\ln \frac{A_{0}}{A}=K t
$$

where $A_{0}\left(\mathrm{mg} \mathrm{L}^{-1}\right)$ is the initial concentration of AG, $A$ (mg $\mathrm{L}^{-1}$ ) is the concentration of AG after different times, and $t(\mathrm{~min})$ is the time.

\section{Effect of initial AG concentration}

The experiment was conducted with different initial concentrations of AG in the presence of $0.05 \mathrm{~g}$ of PANI NT salt/silica composite for $60 \mathrm{~min}$. When the initial concentration of the dye was $1.8 \mathrm{mg} \mathrm{L}^{-1}$, the dye was completely absorbed in $10 \mathrm{~min}$. At higher concentrations, the dye was not completely absorbed, indicating 


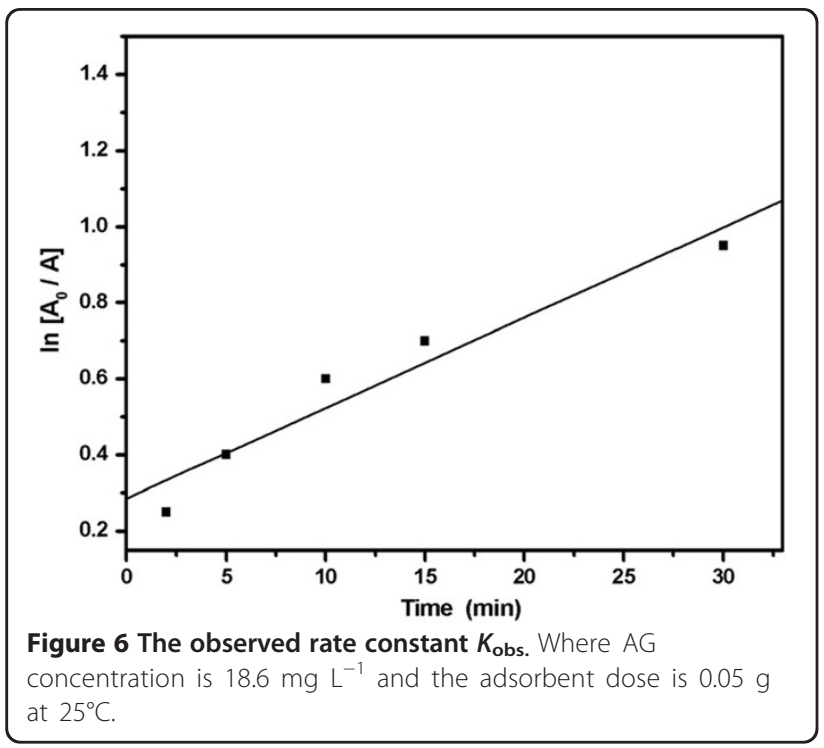

that there is a saturation limit for the polymer, above which it does not remove the dye. The effects of initial concentration and time on the adsorption of AG by PANI NT salt/silica composite are described in Figure 7.

At lower concentrations, all AG present in the adsorption medium could interact with the binding sites on the surface of the adsorbent, so higher adsorption yields were obtained. At higher concentrations, lower adsorption yields were observed because of the saturation of the adsorption sites.

\section{Conclusions}

The adsorption of anionic sulfonated dye AG from aqueous solutions onto PANI NT salt/silica composite was studied with variations in AG concentration. The uptake of the dye was studied using UV-visible spectroscopy. It is concluded that the adsorption amount increases in the

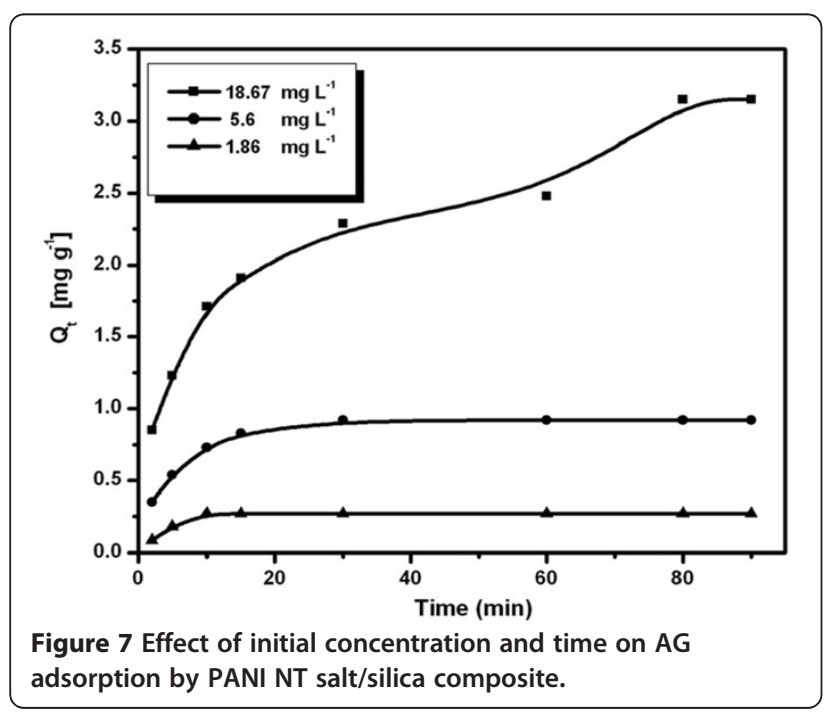

following order: PANI NT salt/silica composite $>$ PANI NT salt $>$ conventional PANI salt/silica composite $>$ conventional PANI salt. This is due to the increase in the surface area of polymer nanotube substrates, and hence, the PANI NT salt/silica composite provides a more efficient adsorbent than the conventional PANI salt/silica composite substrates.

The kinetic models were calculated, and the data showed that the second-order kinetic model is the best linearity with the data more than any other kinetic model. Intraparticle diffusion was likely to take place. The data have been analyzed using the isotherm models, and the data showed that Langmuir is the best linearity with the data more than any other isotherm model.

\section{Methods}

\section{Chemicals}

Aniline (Adwic, Cairo, Egypt) was distilled twice under atmospheric pressure using zinc dust. Ammonium peroxodisulphate (APS) (MP Biomedicals, Santa Ana, CA, USA), acetic acid (Adwic), sulfuric acid (Adwic), silica (60 to 120 meshes with particle size of 0.13 to $0.25 \mathrm{~mm}$ (Aldrich, St. Louis, MO, USA), and acid green 25 (Aldrich) were used without further purification.

\section{Preparation of PANI NT salt/silica composite and conventional PANI salt/silica}

A solution $0.2 \mathrm{~mol} \mathrm{~L}^{-1}$ aniline and $0.25 \mathrm{~mol} \mathrm{~L}^{-1}$ APS in $250 \mathrm{ml}$ of $0.5 \mathrm{~mol} \mathrm{~L}^{-1}$ acetic acid in the presence of 1.8 g silica according to Stjekal's procedure [40] for the preparation of PANI NT salt/silica composite was used. In the present investigation, the composite was prepared as in the bulk. On the following day, the precipitate was collected on a filter paper, rinsed with $0.5 \mathrm{~mol} \mathrm{~L}^{-1}$ acetic acid, and dried. The conventional PANI salt/silica composite was prepared in the bulk solution as described earlier for the PANI NT salt/silica composite, except that

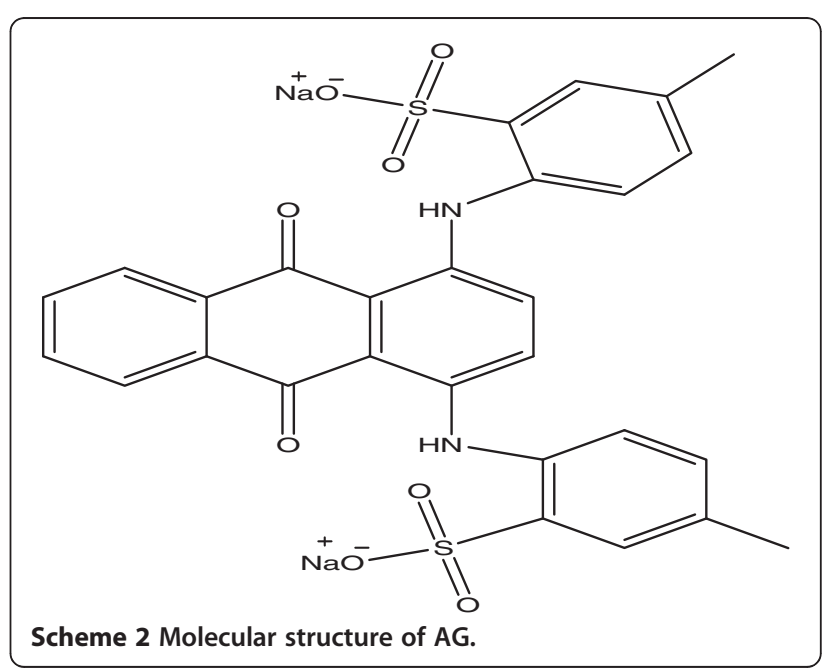


the acetic acid was changed to aqueous sulfuric acid of concentration $0.1 \mathrm{M}$.

\section{Preparation of acid green 25 solution}

The AG has a molecular formula of $\mathrm{C}_{28} \mathrm{H}_{20} \mathrm{~N}_{2} \mathrm{Na}_{2} \mathrm{O}_{8} \mathrm{~S}_{2}$ with a molecular weight of 622.57, and Scheme 2 shows the molecular structure of AG. It is a water-soluble dye that is green in color. A stock solution was prepared by dissolving an appropriate quantity of AG in a volume of distilled water. The working solutions were prepared by diluting the stock solution with distilled water to give the appropriate concentration of the working solutions.

\section{Adsorption experiments and characterization}

UV-visible absorption spectroscopy (Labomed, Inc, Culver City, CA, USA) was used for the determination of the initial and final concentrations of AG solutions by measuring absorbance at $642 \mathrm{~nm}$. Ten-milliliter AG solutions of different concentrations were mixed with $0.05 \mathrm{~g}$ of PANI NT salt/silica composite or conventional PANI salt/silica composite and were stirred at $700 \mathrm{rpm}$ by an electric stirrer for different times in the dark at room temperature. The mixtures of the polymer and dye were separated first by syringe then by a centrifuge (EBA 20, Hitachi, Tokyo, Japan). The morphology of the polymer NTs and their composite with silica were observed with a scanning electron microscope (Fesem Hitachi H-8100). The samples were dispersed in acetone and then transferred onto silicon wafer substrates. The latter was sputtered with a thin layer of $\mathrm{Pt} / \mathrm{Pd}$ at an atomic ratio of 8:2.

\section{Competing interests}

The authors declare that they have no competing interests.

\section{Authors' contributions}

Mohamad M Ayad participated in the sequence alignment and drafted the manuscript and the design of the study and performed the statistical analysis. Ahmed Abu El-Nasr participated in some practical work. All authors read and approved the final manuscript.

\section{Acknowledgements}

Acknowledge to Mohamad M Ayad who contributed by his lab. Also acknowledge to Omid Moradi who is the editor to significant revision of the manuscript.

Received: 29 May 2012 Accepted: 17 June 2012 Published: 6 December 2012

\section{References}

1. Ozcan, AS, Ozcan, A: Adsorption of acid dyes from aqueous solutions onto acid-activated bentonite. J. Colloid Interf. Sci. 276, 39-46 (2004)

2. Baskaralingam, P, Pulikesi, M, Elango, D, Ramamurthi, V, Sivanesan, S: Adsorption of acid dye onto organobentonite. J. Hazard Mater. 128, 138-144 (2006)

3. Mall, ID, Srivastava, VC, Agarwal, NK: Removal of orange-G and methyl violet dyes by adsorption onto bagasse fly ash kinetic study and equilibrium isotherm analyses. Dyes Pigments. 69, 210-223 (2006)

4. Attia, AA, Rashwan, WE, Khedr, SA: Capacity of activated carbon in the removal of acid dyes subsequent to its thermal treatment. Dyes Pigments. 69, 128-136 (2006)
5. Stephenson, RJ, Sheldon, JB: Coagulation and precipitation of mechanical pueffluent.1. removal of carbon and turbidity. Water Res. 30, 781-792 (1996)

6. Chiou, MS, Chuang, GS: Competitive adsorption of dye metanil yellow in acidic solutions on chemically cross-linked chitosan beads. Chemosphere. $62,731-740$ (2006)

7. Forgacs, E, Tibor, C, Gyula, O: Removal of synthetic dyes from wastewaters. Environ. Int. 30, 953-971 (2004)

8. Annadurai, G, Chellapandian, M, Krishnan, MRV: Adsorption of reactive Chitin. Environ. Monit. 59, 111-119 (1999)

9. Namasivayam, C, Muniasamy, N, Gayatri, K, Rani, M, Ranganathan, K: Removal of dyes from aqueous solution by cellulosic waste orange peel. Bioresour. Technol. 57, 37-43 (1996)

10. Namasivayam, C, Prabha, D, Kumutha, M: Removal of direct red and acid brilliant blue by adsorption onto banana pith. Bioresour. Technol. 64, 77-79 (1998)

11. McKay, G, Ramprasad, G, Mowli, PP: Equilibrium studies for the adsorption of dyestuffs from aqueous solutions by low-cost materials. Water. Air. \& Soil Pollution. 29, 273-283 (1986)

12. Ramkrishna, KR, Viaraghavan, T: Dye removal using low cost adsorbents. Water Sci. Technol. 36, 189-196 (1997)

13. Bhattacharya, KG, Sharma, A: Kinetics and thermodynamics of methylene blue adsorption on neem (Azadirachta indica) leaf powder. Dyes Pigm. 65, 51-59 (2005)

14. Dogan, M, Alkan, M, Turkyilmaz, A, Ozdemir, Y: Kinetics and mechanisms of removal of methylene blue by adsorption on perlite. J. Hazard. Mater. 109, 141-148 (2004)

15. Sharma, YC, Uma, SN, Upadhyay, GF: Adsorptive removal of a basic dye from water and wastewater by activated carbon. J. of Applied Science in Environmental Sanitation. 4, 21-24 (2009)

16. Chowdhury, AN, Jesmeen, SR, Hossain, MM: Removal of dyes from water by conducting polymeric adsorbent. Polym. Adv. Technol. 15, 633-638 (2004)

17. Debajyoti, M, Giridhar, M, Radhakrishnan, S, Satish, P: Adsorption and desorption kinetics of anionic dyes on doped polyaniline. J. Phys. Chem. B. 113, 2293-2299 (2009)

18. Mahanta, D, Giridhar, S, Madras, R, Patil, S: Adsorption of sulfonated dyes by polyaniline emeraldine salt and its kinetics. J. Phys. Chem. B. 112, 10153-10157 (2008)

19. MacDiarmid, AG, Chiang, J, Halpern, M, Wu, WS, Somasiri, NLD, Yaniger, Sl: Polyaniline: Interconversion of Metallic and Insulating Forms. Mol. Cryst. Liq. Cryst. 121, 173-180 (1985)

20. Lofton, EP, Thackeray, JW, Wrighton, MS: Amplification of electrical signals with molecule-based transistors: power amplification up to a kilohertz frequency and factors limiting higher frequency operation. J. Phys. Chem. 90, 6080-6083 (1986)

21. Kitani, A, Yano, J, Sasaki, K: ECD materials for the three primary colors developed by polyanilines. J. Electroanal. Chem. 209, 227-232 (1986)

22. Ayad, MM, Salahuddin, NA, Abou-Seif, AK, Alghaysh, MO: Chemical synthesis and characterization of aniline and o-anthranilic acid copolymer. Eur. Polym. J. 44, 426-435 (2008)

23. Miksa, B, Slomkowski, S: Polypyrrole core/polyacrolein shell latex for protein immobilization. Colloid Polym. Sci. 273, 47-52 (1995)

24. Saoudi, B, Jammul, N, Abel, ML, Chehimi, MM, Dodin, G.: DNA adsorption onto conducting polypyrrole. Synth. Met. 87, 97-103 (1997)

25. Wu, MS, Wen, TC, Gopalan, A: In situ UV-visible spectroelectrochemical studies on the copolymerization of diphenylamine with anthranilic acid. Mater Chem Phys. 74, 58-65 (2002)

26. Camalet, JL, Lacroix, JC, Aeiyach, S, Chane-ching, K, Lacaze, PC: Electrosynthesis of adherent polyaniline films on iron and mild steel in aqueous oxalic acid medium. Synth. Met. 93, 133-142 (1998)

27. Salaneck, WR, Huang, WS, Lundstrom, I, MacDiarmid, AG: A two-dimensional surface state diagram for polyaniline. Synth. Met. 13, 291-297 (1986)

28. Paul, EW, Ricco, AJ, Wrighton, WS: Resistance of polyaniline films as a function of electrochemical potential and the fabrication of polyanilinebased microelectronic devices. J. Phys. Chem. 89, 1441-1447 (1985)

29. Liu, XX, Bian, L, Zhang, L, Zhang, L: Composite films of polyaniline and molybdenum oxide formed by electrocodeposition in aqueous media. J. Solid State Electrochem. 11, 1279-1286 (2007)

30. Liu, P, Liu, WM, Xue, QJ: In situ chemical oxidative graft polymerization of aniline from silica nanoparticles. Mater Chem Phys. 87, 109-113 (2004)

31. Feng, XM, Yang, G, Liu, YG, Hou, WH, Zhu, JJ: Electrodeposition of hybrid film of polyaniline/silica and its pseudocapacitive properties. J Appl Polym Sci. 101, 2088-2094 (2006) 
32. Wang, Y, Wang, $X, L i, J, M o, Z$, Zhao, $X$, Jing, $X$, Wang, F: Conductive polyaniline/ silica hybrids from Sol-Gel process. Adv Mater. 13, 1582-1585 (2001)

33. Spinks, GM, Dominis, AJ, Wallace, GG: Comparison of Emeraldine Salt, Emeraldine Base, and Epoxy Coatings for Corrosion Protection of Steel During Immersion in a Saline Solution. CORROSION SCIENCE. 59, 22-31 (2003)

34. Ayad, MM, El-Hefnawey, G, Torad, NL: Quartz crystal microbalance sensor coated with polyaniline emeraldine base for determination of chlorinated aliphatic hydrocarbon. Sens. Actuators B: Chem. 134, 887-894 (2008)

35. Ayad, MM, El-Hefnawey, G, Torad, NL: A sensor of alcohol vapours based on thin polyaniline film and quartz crystal microbalance. J. Hazard. Mat. 168, 85-88 (2009)

36. Ayad, MM, Torad, NL: Alcohol vapours sensor based on thin polyaniline salt film and quartz crystal microbalance. Talanta. 78, 1280-1285 (2009)

37. Tagowska, M, Palys, B, Jackwska, K: Polyaniline nanotubes-anion effect on conformation and oxidation state of polyaniline studied by raman spectroscopy. Synth. Met. 142, 223-229 (2004)

38. Ayad, MM, Prastomo, N, Matsuda, M, Stejskal, J: Sensing of silver ions by nanotubular polyaniline film deposited on quartz-crystal in a microbalance. Synth. Met. 160, 42-46 (2010)

39. Ayad, MM, Abu, E-NA: Adsorption of cationic dye (methylene blue) from water using polyaniline nanotubes base. J. Phys. Chem. C. 114, 14377-14383 (2010)

40. Konyushenko, EN, Stejskal, J, Sedenkova, I, Trchova, M, Sapurina, I, Cieslar, M: Polyaniline nanotubes: the conditions of formation. Polym. Int. 55, 31-33 (2006)

41. Wu, F, Tseng, R, Juang: KineticModeling of liquid-phase adsorption of reactive dyes and metal ions on chitosan. Water Res. 35, 613-618 (2001)

42. Chiou, MS, Li, HY: Equilibrium and kinetic modeling of adsorption of reactive dye on cross-linked chitosan beads. J. Hazard. Mat. 93, 233-248 (2002)

43. Uzun, l: Kinetics of the adsorption of reactive dyes by chitosan. Dyes Pigm. 70, 76-83 (2006)

44. Weber, WJ, Morris, JC: Kinetics of adsorption on carbon from solution. J. Sanit Eng. Div. ASCE. 89, 31-59 (1963)

45. Langmuir, I: The adsorption of gases on plane surfaces of glass, mica and platinum. J. Am. Chem. Soc. 40, 1361-1403 (1918)

46. Langmuir, I: The constitution and fundamental properties of solids and liquids. J. Am. Chem. Soc. 38, 2221-2295 (1916)

47. Weber, TW, Chakravorti, RK: Pore and solid diffusion models for fixed-bed adsorbers. J. Am. Inst. Chem. Eng. 20, 228-238 (1974)

doi:10.1186/2193-8865-3-3

Cite this article as: Ayad and El-Nasr: Anionic dye (acid green 25) adsorption from water by using polyaniline nanotubes salt/silica composite. Journal Of Nanostructure in Chemistry 2012 3:3.

\section{Submit your manuscript to a SpringerOpen ${ }^{\circ}$ journal and benefit from:}

- Convenient online submission

- Rigorous peer review

- Immediate publication on acceptance

- Open access: articles freely available online

- High visibility within the field

- Retaining the copyright to your article

Submit your next manuscript at $\gg$ springeropen.com 